\title{
CATION-INDUCED, INHIBITOR-RESISTANT PHOTOSYSTEM II REACTIONS IN CYANOBACTERIAL MEMBRANES
}

\author{
Cathy L. Selvius DeRoo and Charles F. Yocum \\ Division of Biological Sciences \\ The University of Michigan \\ Ann Arbor, MI 48109
}

Received April 20, 1981

Summary: Ferricyanide-supported oxygen evolution in sonic vesicles from the cyanobacterium Spirulina platensis is only partially sensitive to inhibition by 2,5dibromo-3-methy1-6-isopropy1-p-benzoquinone (DBMIB), and addition of cations to inhibited membranes stjmulates the rate of oxygen evolution. The order of cation effectiveness $\left(M^{3+}>M^{2+}>M^{+}\right)$suggests that this stimulation is due at least in part to surface charge screening effects which permit freer access of anionic ferricyanide to the vesicle membrane surface; $\mathrm{La}^{3+}, \mathrm{Ca}^{2+}$, and $\mathrm{K}^{+}$are most effective in this regard. Ferricyanide photoreduction is completely sensitive to 3-(3,4dichloropheny 1)-1,1-dimethylurea (DCMU), and neither mono- nor divalent cations affect this inhibition. Addition of $\mathrm{La}^{3+}$, on the other hand, causes a nearly complete restoration of ferricyanide-supported oxygen evolution. We conclude that the membrane surfaces of these vesicles are uniquely different from those of higher plants; sites of ferricyanide reduction associated with the interphotosystem chain are surface localized, and the primary acceptor region of photosystem II is susceptible to a trivalent cation-specific reaction in which ferricyanide may directly oxidize the primary acceptor.

Introduction: Cation stimulation of ferricyanide reduction has been observed both in spinach chloroplast and in cyanobacteria. Itoh (1) has presented findings which indicate that Photosystem II reduction of ferricyanide is hindered by electrostatic repulsion between ferricyanide and negative surface charges on thylakoid membranes and that these charges are screened by cations to enhance reduction. Several investigators $(2-5)$ have reported stimulation of ferricyanidemediated $\mathrm{O}_{2}$ evolution by $\mathrm{Ca}^{2+}$ in subcellular preparations of various cyanobacteria, but interactions between the acceptor and the membrane or the possibility of multiple reduction sites have not been reported. Wax and Lockau (6) observed DBMIB-insensi-

Abbreviations: PS, photosystem; SHN, $0.4 \mathrm{M}$ sucrose, $20 \mathrm{mM}$ HEPES (pH 7.5), $15 \mathrm{mM}$ $\mathrm{NaCl}$; ch1, chlorophy11 a; DAD, diaminodurene; DMQ, 2,5-dimethyl-p-benzoquinone; DCMU, 3-(3', 4'-dichloropheny 1)-1,1-dimethylurea; DBMIB, 2,5-dibromo-3-methyl-6isopropyi-p-benzoquinone; MeV, methyl viologen; Asc, ascorbate. 
tive ferricyanide reduction in a thylakoid preparation from Anabaena, a result which suggests the existence of two sites of ferricyanide reduction.

Sonic membranes from Spirulina platensis show cation-mediated stimuiation of electron transport from water to ferricyanide. The order of cation effectiveness in stimulating electron transport is $\mathrm{La}^{3+}>\mathrm{Ca}^{2+}>\mathrm{K}^{+}$, with a ten-fold difference in effective concentration between $\mathrm{La}^{3+}$ and $\mathrm{Ca}^{2+}$. These results suggest the existence of a Guoy-Chapman diffuse double layer effect, in which membrane surface charges are shielded by cations to improve access of ferricyanide to the membrane. We also show that DBMIB can effect partial inhibition of ferricyanide reduction. This inhibition is greatly diminished by cations. More importantly, we show that the inhibition of ferricyanide photoreduction by DCMU is reversed by $\mathrm{La}^{3+}$ addition, but not by $\mathrm{Ca}^{2+}$ or $\mathrm{K}^{+}$. These data are interpreted to indicate that sonic vesicles from Spirulina are accessible to ferricyanide at multiple sites; one of these sites, at the reducing side of PS II, is sensitive to the presence of a trivalent cation.

Materials and Methods: Axenic cultures of Spirulina platensis were grown and harvested as described previously (7), resuspended in SHNI containing $3 \mathrm{mM} \mathrm{MgCl}$, $10 \mathrm{mM} \mathrm{CaCl} 2$, and $2 \mathrm{mg} / \mathrm{ml} \mathrm{BSA}$, and sonicated for 5 minutes in a sait-ice bath. The sonicate was centrifuged $(2,500 \times \mathrm{x}, 10 \mathrm{~min}$.$) to remove debris, and the supernatant$ was centrifuged $(39,000 \mathrm{xg}, 1 \mathrm{hr}$.$) to harvest sonic membranes. The membranes were$ resuspended in SHN and stored at $-70^{\circ} \mathrm{C}$.

Assays of photosynthetic electron transport were conducted in a thermostatted $\left(25^{\circ} \mathrm{C}\right) 1.6 \mathrm{ml}$ cuvette fitted with a Clark-type oxygen electrode. Illumination from two microscope sources was passed through heat filters containing $0.2 \% \mathrm{CuSO}_{4}$ and red filters (cut-on at $600 \mathrm{~nm}$ ) to produce a saturating intensity (approximately $6 \times 10^{6} \mathrm{ergs} / \mathrm{cm}^{2}$. $\mathrm{sec}$ ). The reaction mixture contained $20 \mathrm{mM}$ HEPES ( $\mathrm{pH} 7.5$ ), $0.4 \mathrm{M}$ sucrose, $15 \mathrm{mM} \mathrm{NaCl}$, and $20-27 \mu \mathrm{g} \mathrm{chl}$. Electron acceptors were used at the following concentrations: $2.5 \mathrm{mM}$ ferricyanide, $3.1 \mu \mathrm{M} \mathrm{MeV}, 1.25 \mathrm{mM} \mathrm{DAD}$, and 0.5 $\mathrm{mM}$ DMQ.

Results: Table I presents data showing characteristic photosynthetic electron transport activities of sonic membranes from Spirulina. While the rate of ferricyanide-mediated electron transport with both photosystems active is nearly twice that obtained with methyl viologen as an electron acceptor, inclusion of DMQ with ferricyanide ( in the presence of DBMIB) fails to produce rates of electron transport higher than those observed with ferricyanide alone. Neither DMQ nor PD 
Table 1. Characteristic photosynthetic electron transport activities of sonic particles from Spirulina platensis.

\begin{tabular}{lc}
\hline Assay & Rate (umoles $\left.0_{2} / \mathrm{hr} \cdot \mathrm{mg} \mathrm{ch}\right)$ \\
\hline $\mathrm{H}_{2} \mathrm{O} \rightarrow \mathrm{Fe}(\mathrm{CN})_{6}^{3-}$ & 134 \\
$\mathrm{H}_{2} \mathrm{O} \rightarrow \mathrm{OMO} \rightarrow \mathrm{Fe}(\mathrm{CN})_{6}^{3-}$ & $100^{1}$ \\
$\mathrm{H}_{2} \mathrm{O} \rightarrow \mathrm{MeV}$ & 73 \\
$\mathrm{AsC} / \mathrm{DAD} \rightarrow \mathrm{MeV}$ & $837^{2}$ \\
\hline
\end{tabular}

1plus $2 \mu$ M DBMIB

2plus $6.2 \mu M$ DCMU

(data not shown) produced the stimulations of electron transport which have been observed in spinach thylakoid membranes (8).

The sensitivity of electron transport in Spirulina sonic vesicles to inhibition by DBMIB was determined for both ferricyanide and methyl viologen mediated reactions (Fig. 1). While electron transport to methyl viologen is completely sensitive to concentrations of DBMIB as low as $0.5 \mu \mathrm{M}$, ferricyanide-mediated electron transport is only partially sensitive to DBMIB. The addition of $6.2 \mathrm{mM} \mathrm{CaCl} 2$ (Fig. 1) results in an increase in the rate of electron transport to ferricyanide in the absence of DBMIB (from 140 to 240 moles $0_{2} / \mathrm{hr} \cdot \mathrm{mg} \mathrm{chl}$ ) and in diminished sensitivity to DBMIB, suggesting that substantial ferricyanide reduction is occurring prior to the DBMIB inhibition site, and that $\mathrm{Ca}^{2+}$ enhances this reaction.

An examination of the effects of trivalent, divalent, and monovalent cations $\left(\mathrm{La}^{3+}, \mathrm{Ca}^{2+}, \mathrm{K}^{+} ; \mathrm{a} 11\right.$ chloride salts) on the rate of ferricyanide-mediated electron transport in the presence of $2.0 \mu \mathrm{M}$ DBMIB produced the data shown in Figure 2, where $\mathrm{La}^{3+}$ was more effective in stimulating electron transport at lower effective concentrations than were divalent or monovalent cations. Save for the much higher rate of $\mathrm{O}_{2}$ evolution in the Spirulina preparation, these results are in agreement with data obtained by Itoh (1) for sonicated thylakoid membranes. We have examined a number of cations using DBMIB-poisoned membranes: while several trivalent cations $\left(\mathrm{La}^{3+}, \mathrm{Yb}^{3+}, \mathrm{Pr}^{3+}\right)$ were equally effective in stimulating oxygen evolution in the 


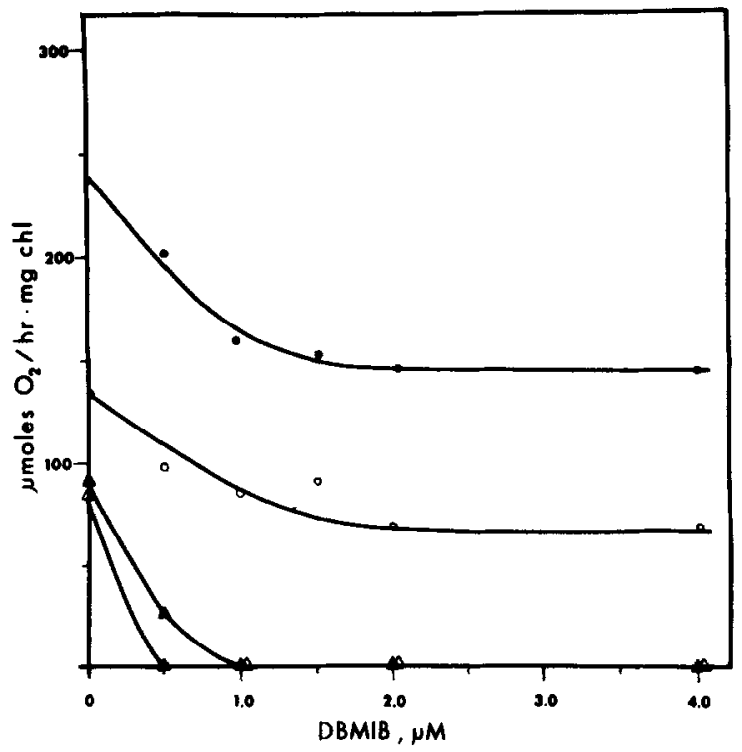

Figure 1. Inhibition of photosynthetic electron transport by DBMIB. Assay conditions are as given in Materials and Methods with the exception of the following: (o) ferricyanide; (•) ferricyanide $+6.2 \mathrm{mM} \mathrm{CaCl}$; ( 4 ) $\mathrm{MeV}$;

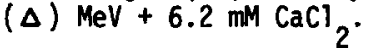

presence of DBMIB, $\mathrm{Mg}^{2+}$ was less effective than $\mathrm{Ca}^{2+}$, and $\mathrm{Na}^{+}$was less effective than $\mathrm{K}^{+}$under the conditions of assay we report here. In addition, the data of Figure 2 show that both $\mathrm{La}^{3+}$ and $\mathrm{Ca}^{2+}$ will inhibit oxygen evolution at higher

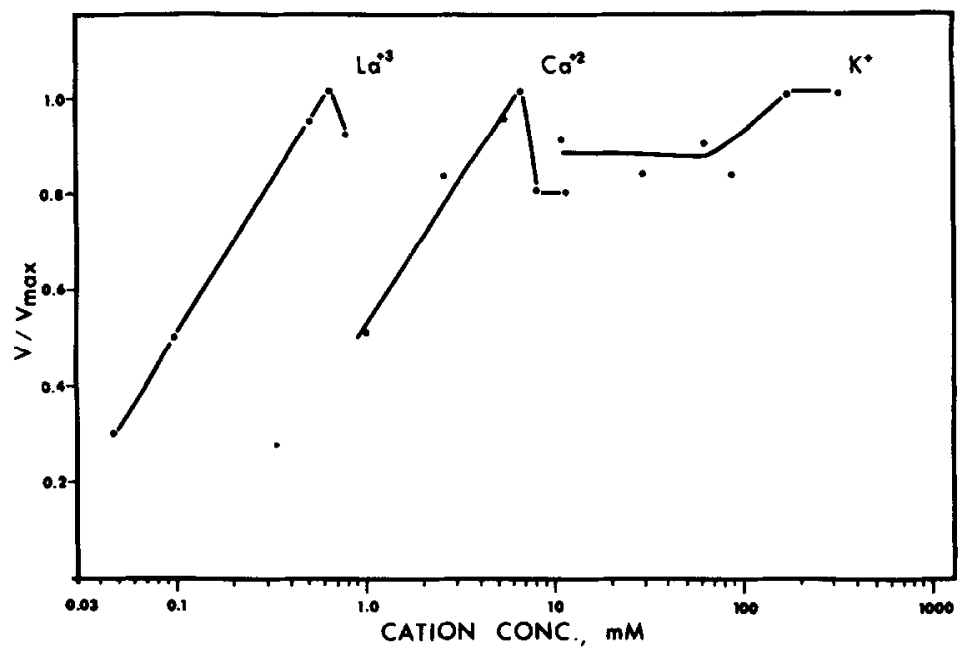

Figure 2. Effect of cations on the rate of ferricyanide reduction. All experiments were performed in the presence of $2 \mu \mathrm{M}$ DBMIB. Vmax values are as follows: La ${ }^{+}: 277$ umales $0_{2} / \mathrm{hr} \cdot \mathrm{mg} \mathrm{chl} ; \mathrm{Ca}^{2+}$ : 115 moles $\mathrm{O}_{2} / \mathrm{hr} \cdot \mathrm{mg} \mathrm{chl}$; $\mathrm{K}^{+}: 81$ umoles $\mathrm{O}_{2} / \mathrm{hr} \cdot \mathrm{mg} \mathrm{chl}$. 


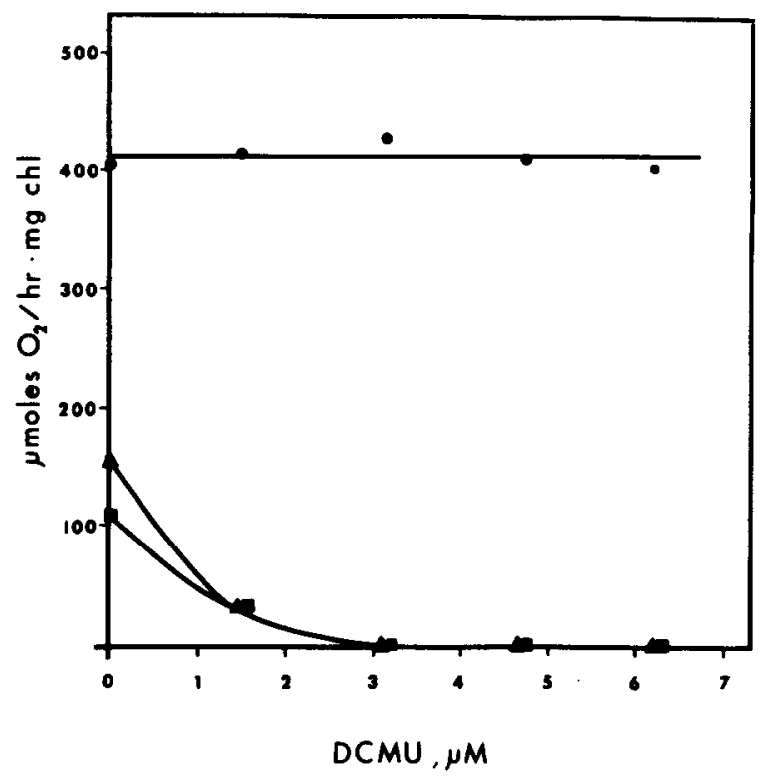

Figure 3. Inhibition of photosynthetic electron transport to ferricyanide by DCMU. Assay conditions are as given in Materials and Methods with the exception

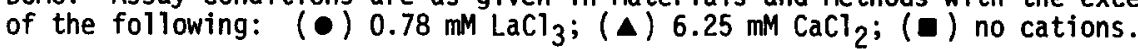

concentrations (>0.6 $\mathrm{mM}$ for $\mathrm{La}^{3+},>6.0 \mathrm{mM}$ for $\mathrm{Ca}^{2+}$ ). We cannot explain this effect at the present time.

In order to further define the PS II-associated site of ferricyanide reduction, the sensitivity of electron transport to DCMU was determined. Ferricyanide-mediated electron transport is completely inhibited by $3.0 \mu \mathrm{M} \mathrm{DCMU}$ (Fig. 3), both in the

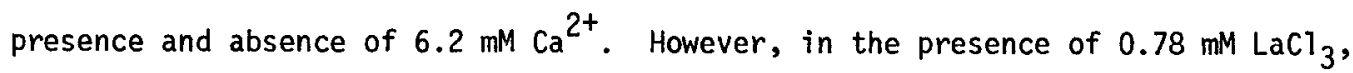
ferricyanide reduction is completely insensitive to inhibition by DCMU, even at concentrations as high as $6.25 \mu M$, although methyl viologen reduction is completely sensitive to DCMU under assay conditions (Table II) where $\mathrm{La}^{3+}$ or $\mathrm{Ca}^{2+}$ are also present. The data of Table II show that the rate of methyl viologen reduction is depressed by cation additions. This effect, seen at cation concentrations similar to those shown in Fig. 2, suggests that tri- and divalent cations must act at multiple sites in these sonic membranes to produce both stimulatory and inhibitory effects on electron flow; the nature of the effect may depend on the acceptor employed for assay. 
Table 2. Inhibition of photosynthetic electron transport to methyl viologen by DCMU in the presence and absence of cations.

\begin{tabular}{lc}
\hline Additions & Rate (umoles $0_{2} / \mathrm{hr} \cdot \mathrm{mg} \mathrm{chl}$ ) \\
\hline None & 105 \\
$\mathrm{DCMU}$ & 0 \\
$\mathrm{CaCl}_{2}$ & 90 \\
$\mathrm{CaCl}_{2}+\mathrm{DCMU}$ & 0 \\
$\mathrm{LaCl}_{3}$ & 47 \\
$\mathrm{LaCl}_{3}+\mathrm{DCMU}$ & 0 \\
\hline
\end{tabular}

Assay conditions are given under Materials and Methods. Methyl viologen $(3.1 \mu \mathrm{M})$ was used as an electron acceptor. The concentrations of $\mathrm{CaCl}_{2}$ and $\mathrm{LaCl}_{3}$ used were $6.2 \mathrm{mM}$ and $0.78 \mathrm{mM}$, respectively; when present, the DCFU concentration was $1.5 \mu \mathrm{M}$.

Discussion: Photosystem II-dependent electron transport to ferricyanide in sonic membranes from Spirulina platensis is stimulated by cations both in the presence and absence of DBMIB; similar concentrations of these cations depress, rather than enhance the rate of methyl viologen reduction (Table II). In stimulating electron transport to ferricyanide, $\mathrm{La}^{3+}$ is more effective than $\mathrm{Ca}^{2+} ; \mathrm{K}^{+}$is least effective. The difference in effective concentration between $\mathrm{La}^{3+}$ and $\mathrm{Ca}^{2+}$ is ten-fold and may be evidence for a Guoy-Chapman diffuse double layer effect; i.e., the negatively charged membrane is shielded by the cations, thus improving accessibility of the trivalently anionic ferricyanide molecule to the membrane. The exact mechanism for this apparent screening effect may include binding of $\mathrm{La}^{3+}$ to neutralize surface charge, and experiments are now in progress to further define this phenomenon. The observation that $\mathrm{La}^{3+}$ is capable of affecting the membranes of these sonic vesicles to produce DCMU-insensitive electron transport is rather surprising. In a previous study Itoh (1) was able to show that sonicated spinach thylakoid membranes were accessible to ferricyanide in a cation-dependent, DBMIB-insensitive reaction but this phenomenon was due to surface charge screening, as was the ferricyanide-mediated dark reoxidation of the PS II primary acceptor in intact membranes(9) Other investigators $(10,11)$ have shown that silicomolybdate is photoreduced by 
spinach chloroplasts in a DCMU-insensitive reaction; however, the lipophilicity of this compound provides a likely explanation for its activity. In the Spirulina preparations we describe here, a trivalent cation, at low concentrations, produces high rates of DCMU-insensitive electron flow to an anionic oxidant.

The $\mathrm{La}^{3+}$ effect we report here is seen with other trivalent cations $\left(\mathrm{Yb}^{3+}\right.$, $\left.\mathrm{Pr}^{3+}\right)$, and the PS II inhibition imposed by atrazine is also reversed by these cations (data not shown). The inability of $\mathrm{Ca}^{2+}$ at any concentration to reverse DCMU inhibition of electron flow in the Spirulina preparations shows that the $\mathrm{La}^{3+}$ effect is unrelated to surface charge screening effects. Rather, it appears likely that trivalent cations are capable of modifying the environment of the primary acceptor in such a way as to permit direct access of ferricyanide to this site of photoreduction. Our data have identified multiple sites of ferricyanide reduction in these vesicles, and we are now characterizing the properties of these sites. The phenomena presented here may be due at least in part to the sonication treatment used to prepare Spirulina membranes. However, in work to be presented elsewhere, (S.J. Robinson, C.L. Selvius DeRoo, and C.F. Yocum, in preparation) we will show that some of the cation-mediated effects on ferricyanide photoreduction have also been observed in intact cells of this organism.

Acknowledgment: This research was supported by the Science and Education Administration of the U.S. Department of Agriculture under Grant No. 5910-0010-8-0103-0 from the Competitive Grants Research Office.

\section{References:}

1. Itoh, S. (1978) Plant Cell Physiol. 19, 149-166.

2. Piccioni, R.G. and Mauzeral1, D.C. (1978) Biochim. Biophys. Acta 504, 384-397.

3. Piccioni, R.G. and Mauzeral1, D.C. (1978) Biochim. Biophys. Acta 504, 398-405.

4. Diner, B.A. and Mauzera 1 1, D.C. (1971) Biochim. Biophys. Acta 226, 492-497.

5. Brand, J.J. (1979) FEBS Lett. 103, 114-117.

6. Wax, E. and Lockau, W. (1980) Z. Naturforsh. 35c, 98-105.

7. Owers-Narhi, L., Robinson, S.J., Selvius DeRoo, C., and Yocum, C.F. (1979) Biochem. Biophys. Res. Commun. 90, 1025-1031.

8. Saha, S., Ouitrakul, R., Izawa, S., and Good, N.G. (1971) J. Biol. Chem. 246, 3204-3209.

9. Itoh, S. (1978) Biochim. Biophys. Acta 504. 324-340.

10. Barr, R., Crane, F.L., and Giaquinta, R.T. (1975) Plant Physiol. 55. 460-462.

11. Berg, S.P. and Izawa, S. (1977) Biochim. Biophys. Acta $460,206-\overline{219}$. 